Case Report

\title{
Multiple Gastric Gastrointestinal Stromal Tumors in a Patient with Neurofibromatosis Type 1
}

\author{
Makoto Tomatsu, ${ }^{1}$ Jun Isogaki, ${ }^{1}$ Takahiro Watanabe, ${ }^{1}$ Kiyoshige Yajima, ${ }^{1}$ \\ Takuya Okumura, ${ }^{1}$ Kimihiro Yamashita, ${ }^{1}$ Kenji Suzuki, ${ }^{1}$ Akihiro Kawabe, ${ }^{1}$ \\ Akira Komiyama, ${ }^{2}$ and Seiichi Hirota ${ }^{3}$ \\ ${ }^{1}$ Department of Surgery, Fujinomiya City General Hospital, 3-1 Nishiki-cho, Fujinomiya, Shizuoka 418-0076, Japan \\ ${ }^{2}$ Department of Diagnostic Pathology, Fujinomiya City General Hospital, 3-1 Nishiki-cho, Fujinomiya, Shizuoka 418-0076, Japan \\ ${ }^{3}$ Department of Surgical Pathology, Hyogo College of Medicine, 1-1 Mukogawa-cho, Nishinomiya, Hyogo 663-8501, Japan
}

Correspondence should be addressed to Makoto Tomatsu; tomatsumakoto@gmail.com

Received 16 February 2016; Accepted 16 May 2016

Academic Editor: Tahsin Colak

Copyright (C) 2016 Makoto Tomatsu et al. This is an open access article distributed under the Creative Commons Attribution License, which permits unrestricted use, distribution, and reproduction in any medium, provided the original work is properly cited.

\begin{abstract}
Gastrointestinal stromal tumors (GISTs) are relatively common in neurofibromatosis type 1 (NF 1) patients. Approximately $90 \%$ of GISTs associated with NF 1 are located in the small intestine, while sporadic GISTs are most commonly located in the stomach. Here we report an extremely rare case of an NF 1 patient with multiple gastric GITs ( 90 or more) but without multiple small intestinal tumors. A 63-year-old female patient who had a history of NF 1 underwent surgery for a gastric neuroendocrine tumor and gastric submucosal tumor (SMT). During the operation, multiple small nodules were identified on the serosal surface of the upper stomach. SMT and multiple nodules on the serosal surface were diagnosed as GISTs consisting of spindle cells positive for KIT, CD34, and DOG-1. Both GIST and the normal gastric mucosa showed no mutations not only in the c-kit gene (exons 8, 9, 11, 13, and 17) but also in the PDGFRA gene (exons 12,14, and 18). This patient is being followed up without the administration of a tyrosine kinase inhibitor.
\end{abstract}

\section{Introduction}

Neurofibromatosis type 1 (NF 1) is one of the most common autosomal dominant traits, with a rate of occurrence of approximately 1 in 4000 in the general population [1]. The cause of NF 1 is a mutation in the NF 1 gene that encodes neurofibromin. Because neurofibromin inhibits Ras oncogene activity, the loss of neurofibromin function results in Ras activation and subsequent tumor formation [2].

Gastrointestinal stromal tumors (GISTs) are relatively common with prevalences estimated to vary from $5 \%$ to $30 \%$ in NF 1 patients [1]. Approximately 90\% of GISTs associated with NF 1 are located in the small intestine, and only $5.4 \%$ are located in the stomach [3].

In this paper, an extremely rare case of multiple gastric GISTs in an NF 1 patient is reported.

\section{Case Report}

A 63-year-old female was examined for dysphagia. She and her father had a history of NF 1 . The patient presented with multiple neurofibromas and some cafe-au-lait spots all over her body (Figure 1(a)).

Upper gastrointestinal endoscopy revealed a neuroendocrine tumor (NET) located on the posterior side of the upper gastric wall and a submucosal tumor (SMT) located on the greater curvature of the middle gastric wall (Figures $1(\mathrm{~b})$ and 1(c)). Computed tomography (CT) indicated only SMT, which was approximately $30 \mathrm{~mm}$ in diameter and had a smooth surface (Figure 1(d)). CT did not show NET or any other lesion.

Preoperative diagnosis was a gastric NET in combination with a gastric SMT suspected to be GIST. Laparoscopic 


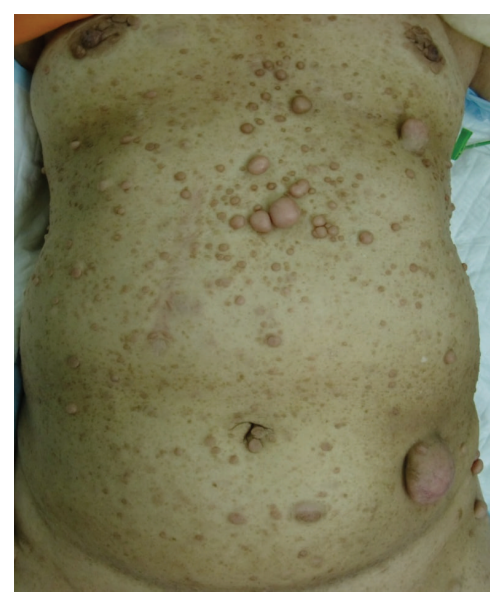

(a)

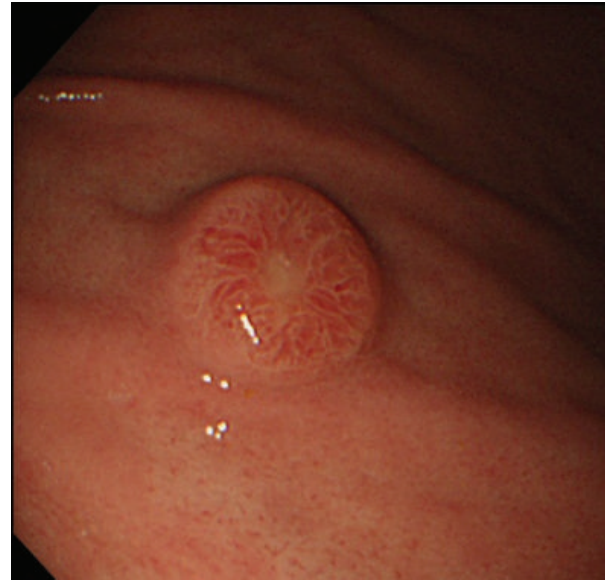

(b)

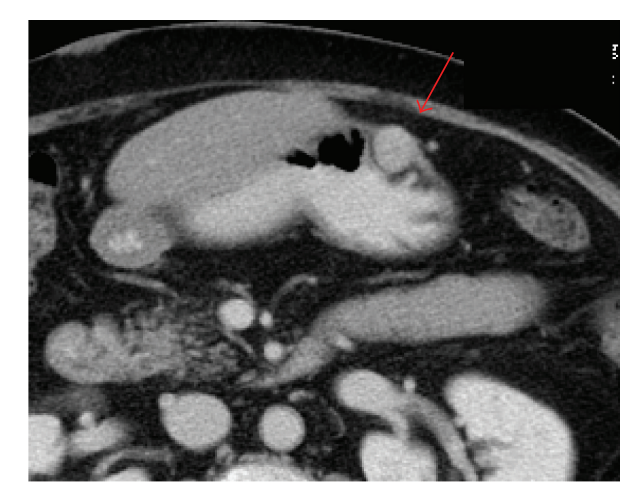

(d)

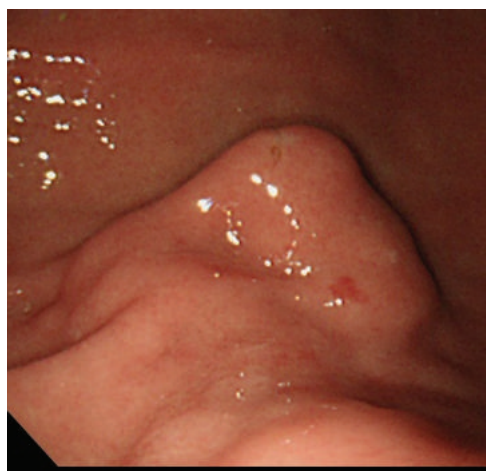

(c) shows neuroendocrine tumor located on posterior side of upper gastric wall. The size was about $10 \mathrm{~mm}$. (c) And submucosal tumor located on greater curvature side of middle gastric wall. The size was about $30 \mathrm{~mm}$. (d) Computed tomography showed only a SMT (arrow); the size was about $30 \mathrm{~mm}$ and the surface was smooth. Other lesions could not be pointed out.

proximal gastrectomy with $\mathrm{D} 1+$ lymph node dissection for NET and partial gastrectomy for SMT were planned.

During the operation, multiple small nodules were identified on the serosal surface of the upper stomach (Figure 2). Most nodules were resected by proximal gastrectomy. There were no apparent abnormalities on the serosal surface of the small intestine or colorectum.

The result of a histopathological examination of the upper gastric lesion was consistent with NET G1; the MIB-1 index was $2 \%$, without any lymph node metastases. In contrast, SMT of the middle gastric wall contained two intramural lesions $(1.4 \times 1.2 \mathrm{~cm}$ and $0.8 \times 0.6 \mathrm{~cm})$. These SMTs were compatible with GISTs; three mitotic figures in $50 \mathrm{HPF}$ were seen. There were no findings indicating tumor rupture in these two lesions (Figure 3(a)). There were 90 or more small nodules on the gastric serosal surface, which were diagnosed as GISTs. These consisted of spindle cells positive for KIT (CD117), CD34, and DOG-1 (Figures 3(b) and 4). All these small nodules located under the serosa confirm that they were not a peritoneal metastasis.

Analyses of the c-kit gene and platelet-derived growth factor receptor $\alpha$ (PDGFRA) gene were performed in one

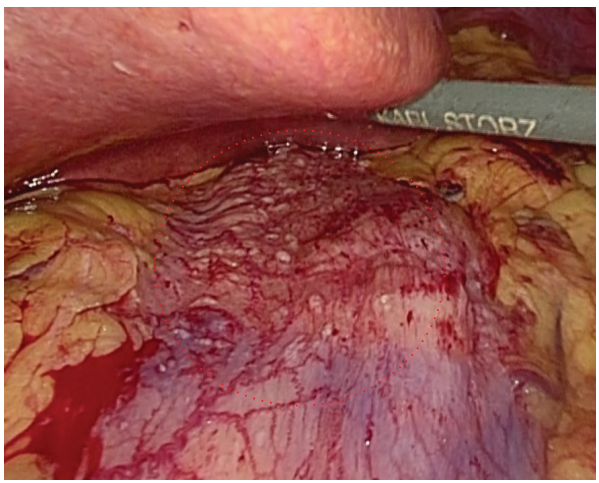

FIgURE 2: Intraoperative picture. There were multiple small nodules on serosal surface of upper stomach.

GIST. There were no alterations in either the c-kit gene (exons $8,9,11,13$, and 17) or PDGFRA gene (exons 12, 14, and 18). The patient's normal gastric mucosal tissue also showed no mutations in the c-kit gene (exons $8,9,11,13$, and 17) or PDGFRA gene (exons 12,14, and 18), confirming that this was 


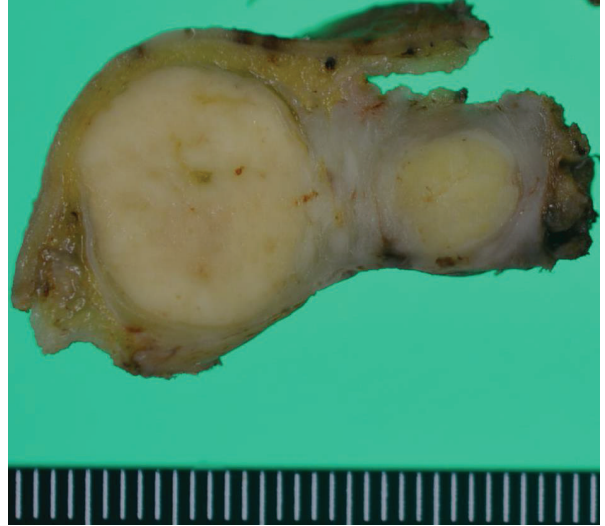

(a)

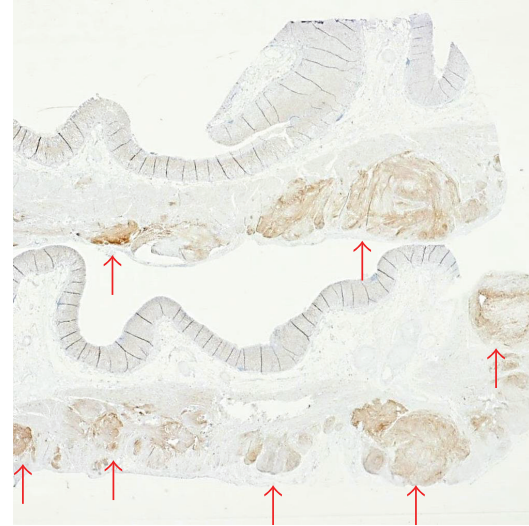

(b)

FIGURE 3: (a) SMT of the middle gastric wall contained two intramural lesions $(1.4 \times 1.2 \mathrm{~cm}$ and $0.8 \times 0.6 \mathrm{~cm})$. There were no findings indicating tumor rupture in these two lesions. (b) Multiple nodules located in subserosa of upper stomach. These nodules were positive for KIT (CD117).

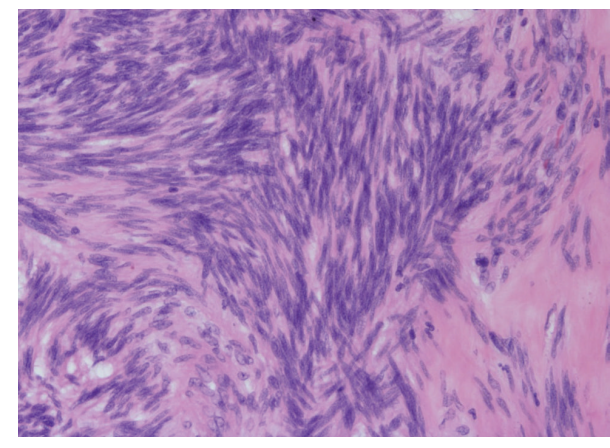

(a)

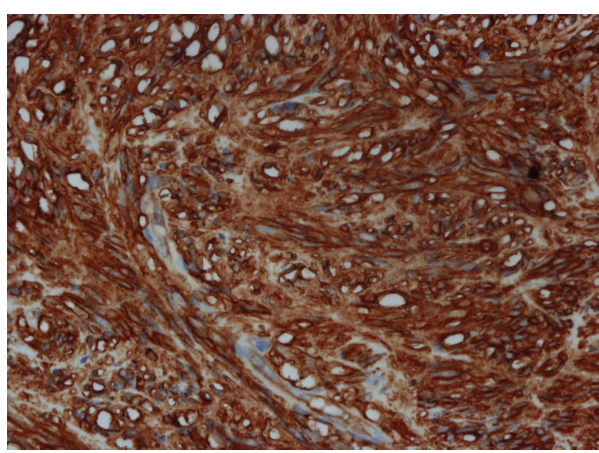

(c)

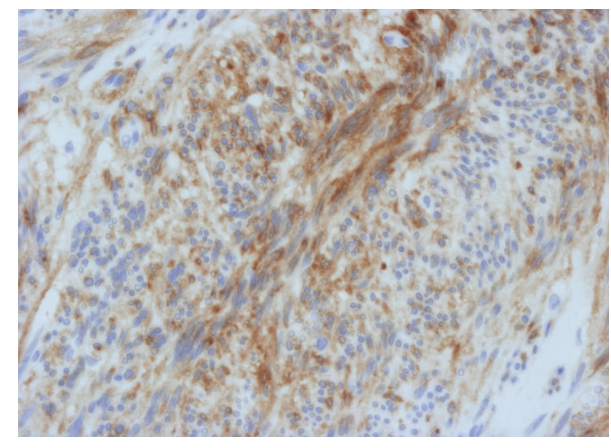

(b)

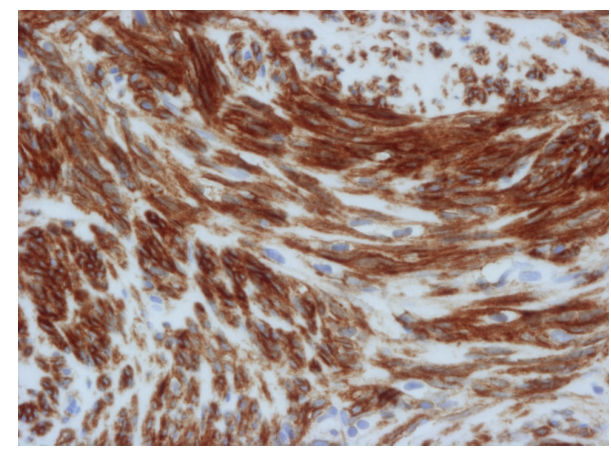

(d)

FIgure 4: Histopathological analysis. (a) The tumors consisted of spindle cells. (b) Positive for KIT (CD117). (c) Positive for CD34. (d) Positive for DOG-1.

not a case of familial GISTs with a germline mutation in the c-kit or PDGFRA gene.

The patient is being followed up without the administration of a tyrosine kinase inhibitor.

\section{Discussion}

GIST is the most common mesenchymal tumor in the digestive tract, originating from the interstitial cell of Cajal [4]. Sporadic GISTs are most commonly located in the stomach
(60-70\% of cases), followed by the small intestine (20-25\%) and other locations [5]. In sporadic GISTs, $85-90 \%$ of cases have mutations in the c-kit gene. In addition, $35-62.5 \%$ of cases without c-kit gene mutations have mutations in the PDGFRA gene [6].

On the other hand, GISTs in NF 1 patients differ from sporadic GISTs in several aspects. A PubMed search of the literature revealed 126 case reports concerning GISTs associated with NF 1 (keywords: "Gastrointestinal stromal tumor" and "Neurofibromatosis 1"; language: English). Only 
TABLE 1: Cases of gastric GISTs in patients with NF 1.

\begin{tabular}{|c|c|c|c|c|c|c|c|c|c|}
\hline \multirow{2}{*}{\multicolumn{2}{|c|}{ Case number Age }} & \multirow{2}{*}{ Sex } & \multirow{2}{*}{ Total number of GISTs } & \multirow{2}{*}{ Site } & \multirow{2}{*}{ Number of GISTs } & \multirow{2}{*}{ Size $(\mathrm{cm})$} & \multicolumn{2}{|c|}{ Genetic analysis } & \multirow{2}{*}{ Reference number } \\
\hline & & & & & & & $c$-kit & PDGFRA & \\
\hline \multirow{2}{*}{1} & \multirow{2}{*}{32} & \multirow{2}{*}{$\mathrm{F}$} & \multirow{2}{*}{4} & Stomach & ND & \multirow{2}{*}{$2-10$} & \multirow{2}{*}{$\mathrm{NE}$} & \multirow{2}{*}{ NE } & \multirow{2}{*}[7]{} \\
\hline & & & & Jejunum & ND & & & & \\
\hline \multirow{3}{*}{2} & \multirow{3}{*}{82} & \multirow{3}{*}{$\mathrm{F}$} & \multirow{3}{*}{ Numerous } & Stomach & ND & \multirow{3}{*}{$0.5-2.5$} & \multirow{3}{*}{ WT } & \multirow{3}{*}{ WT } & \multirow{3}{*}[7]{} \\
\hline & & & & Small intestine & ND & & & & \\
\hline & & & & Colon & ND & & & & \\
\hline \multirow{4}{*}{3} & \multirow{4}{*}{77} & \multirow{4}{*}{$\mathrm{M}$} & \multirow{4}{*}{5} & Stomach & $\mathrm{ND}$ & \multirow{4}{*}{$0.3-2.0$} & \multirow{4}{*}{ WT } & \multirow{4}{*}{ WT } & \multirow{4}{*}{ [7] } \\
\hline & & & & Esophagus & ND & & & & \\
\hline & & & & Jejunum & ND & & & & \\
\hline & & & & Ileum & $\mathrm{ND}$ & & & & \\
\hline & & & & Stomach & $\mathrm{ND}$ & & & & \\
\hline 4 & 64 & $\mathrm{M}$ & $>100$ & Small intestine & ND & $0.1-3.5$ & WT & WT & [7] \\
\hline & & & & Colon & $\mathrm{ND}$ & & & & \\
\hline 5 & 58 & $M$ & 5 & Stomach & 2 & $0.3,3.0$ & WT & WT & {$[8]$} \\
\hline & & 101 & J & ND & 3 & $\mathrm{ND}$ & N & r 1 & {$[0]$} \\
\hline 6 & 64 & $\mathrm{~F}$ & Multiple & Stomach & 1 & 11 & WT & WT & [9] \\
\hline 0 & & & & Small intestine & Multiple & Maximum 3.5 & & & [9] \\
\hline 7 & 40 & $\mathrm{~F}$ & 1 & Stomach & 1 & 2.5 & WT & WT & {$[10]$} \\
\hline 8 & 67 & $\mathrm{M}$ & 1 & Stomach & 1 & Voluminous & $\mathrm{NE}$ & $\mathrm{NE}$ & [11] \\
\hline 9 & 71 & $\mathrm{M}$ & 1 & Stomach & 1 & 3.6 & $\mathrm{NE}$ & $\mathrm{NE}$ & [3] \\
\hline 10 & 38 & $\mathrm{~F}$ & 1 & Stomach & 1 & 8 & $\mathrm{NE}$ & $\mathrm{NE}$ & [12] \\
\hline 11 & 59 & $\mathrm{~F}$ & 4 & Stomach & 2 & $0.2,0.5$ & WT & W] & \\
\hline & 59 & $\mathrm{~F}$ & 4 & Jejunum & 2 & $0.8,3.0$ & W 1 & W 1 & 1] \\
\hline
\end{tabular}

ND: not described, NE: not examined, and WT: wild type.

$11(8.7 \%)$ patients had gastric GISTs (Table 1) [1, 3, 7-12], of whom seven had multiple GISTs in the stomach and four had only one gastric GIST. Six patients also had GISTs in the small intestine. One patient had GISTs on another site, but with no description of the site involved. In contrast, 120 (95.2\%) patients had GISTs in the small intestine, including the duodenum. In addition, there were two or more GISTs in $82(65.1 \%)$ patients. Mutations in the c-kit gene were detected in only 2 of 51 patients (3.9\%), and those in the PDGFRA gene were not detected (0/47). Thus, typical GISTs associated with NF 1 are located in the small intestine, show multiplicity, and have a mutation in neither the c-kit nor PDGFRA gene. Our NF 1 case with more than 90 GISTs on the serosal surface of the stomach is extremely unusual. To the best of our knowledge, there are no similar case reports.

GISTs associated with NF 1 are generally of low grade [3]. Our NF 1 case was also of low grade, with a maximum GIST size of $1.4 \mathrm{~cm}$ and with $3 / 50 \mathrm{HPF}$ mitotic figures. In addition, GISTs without a mutation in the $c-k i t / P D G F R A$ gene appear to respond less well to a tyrosine kinase inhibitor than GISTs with this mutation. Therefore, a tyrosine kinase inhibitor may show no effect on GISTs associated with NF 1 [13]. In our case, left lesions or recurrences on the residual stomach were the major concerns. Nevertheless, we did not perform adjuvant chemotherapy with a tyrosine kinase inhibitor because the resected GISTs were low risk and a response to a tyrosine kinase inhibitor could not be guaranteed. For GISTs with NF 1 , the importance of a routine follow-up is unknown. Our plan of follow-up for our patient is CT every 6 months for 5 years. When recurrences are detected, we will observe them unless they cause some symptoms such as obstruction or bleeding because multiple and metachronal recurrences are anticipated.

Familial and multiple GISTs caused by germline mutations in the c-kit or PDGFRA gene have been reported [14]. In such situations, multiple GISTs develop in both the stomach and the small intestine. All multiple GISTs have the same mutation in the c-kit or PDGFRA gene. Moreover, patients display the same mutation, even in the normal tissue. In the current case report, there was no mutation in the c-kit or PDGFRA gene not only in the GIST tissue but also in the normal gastric mucosa. This indicates that this is not a case of familial GISTs caused by germline mutations in the c-kit or PDGFRA gene.

In summary, we encountered an extremely rare case of multiple gastric GISTs associated with NF 1.

\section{Competing Interests}

The authors declare that there are no competing interests regarding the publication of this paper. 


\section{References}

[1] M. Vlenterie, U. Flucke, L. C. Hofbauer et al., "Pheochromocytoma and gastrointestinal stromal tumors in patients with neurofibromatosis type I," The American Journal of Medicine, vol. 126, no. 2, pp. 174-180, 2013.

[2] A. Gorgel, D. D. Cetinkaya, F. Salgur et al., "Coexistence of gastrointestinal stromal tumors (GISTs) and pheochromocytoma in three cases of neurofibromatosis type 1 (NF1) with a review of the literature," Internal Medicine, vol. 53, no. 16, pp. 1783-1789, 2014.

[3] P. F. Salvi, L. Lorenzon, S. Caterino, L. Antolino, M. S. Antonelli, and G. Balducci, "Gastrointestinal stromal tumors associated with neurofibromatosis 1: a single centre experience and systematic review of the literature including 252 cases," International Journal of Surgical Oncology, vol. 2013, Article ID 398570, 8 pages, 2013.

[4] S. Hirota, K. Isozaki, Y. Moriyama et al., "Gain-of-function mutations of c-kit in human gastrointestinal stromal tumors," Science, vol. 279, no. 5350, pp. 577-580, 1998.

[5] M. Miettinen and J. Lasota, "Gastrointestinal stromal tumorsdefinition, clinical, histological, immunohistochemical, and molecular genetic features and differential diagnosis," Virchows Archiv, vol. 438, no. 1, pp. 1-12, 2001.

[6] K. Isozaki and S. Hirota, "Gain-of-function mutations of receptor tyrosine kinases in gastrointestinal stromal tumors," Current Genomics, vol. 7, no. 8, pp. 469-475, 2006.

[7] J. Andersson, H. Sihto, J. M. Meis-Kindblom, H. Joensuu, N. Nupponen, and L.-G. Kindblom, "NF1-associated gastrointestinal stromal tumors have unique clinical, phenotypic, and genotypic characteristics," The American Journal of Surgical Pathology, vol. 29, no. 9, pp. 1170-1176, 2005.

[8] Y. Takazawa, S. Sakurai, Y. Sakuma et al., "Gastrointestinal stromal tumors of neurofibromatosis type I (von Recklinghausen's disease)," The American Journal of Surgical Pathology, vol. 29, no. 6, pp. 755-763, 2005.

[9] M. Miettinen, J. F. Fetsch, L. H. Sobin, and J. Lasota, "Gastrointestinal stromal tumors in patients with neurofibromatosis 1: a clinicopathologic and molecular genetic study of 45 cases," The American Journal of Surgical Pathology, vol. 30, no. 1, pp. 90-96, 2006.

[10] B. Liegl, J. L. Hornick, C. L. Corless, and C. D. M. Fletcher, "Monoclonal antibody DOG1.1 Shows higher sensitivity than KIT in the diagnosis of gastrointestinal stromal tumors, including unusual subtypes," American Journal of Surgical Pathology, vol. 33, no. 3, pp. 437-446, 2009.

[11] G. Cavallaro, U. Basile, A. Polistena et al., "Surgical management of abdominal manifestations of type 1 neurofibromatosis: experience of a single center," American Surgeon, vol. 76, no. 4, pp. 389-396, 2010.

[12] S. K. Swain, R. Smile, T. Arul, and D. David, "Unusual presentation of gastrointestinal stromal tumor of stomach in neurofibromatosis type 1: a case report," Indian Journal of Surgery, vol. 75, no. 1, pp. 398-400, 2013.

[13] K. Kinoshita, S. Hirota, K. Isozaki et al., "Absence of ckit gene mutations in gastrointestinal stromal tumours from neurofibromatosis type 1 patients," The Journal of Pathology, vol. 202, no. 1, pp. 80-85, 2004.

[14] K. Yamanoi, K. Higuchi, H. Kishimoto et al., "Multiple gastrointestinal stromal tumors with novel germline c-kit gene mutation, K642T, at exon 13," Human Pathology, vol. 45, no. 4, pp. 884-888, 2014. 


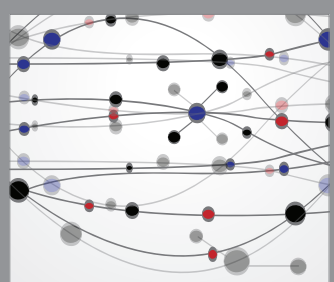

The Scientific World Journal
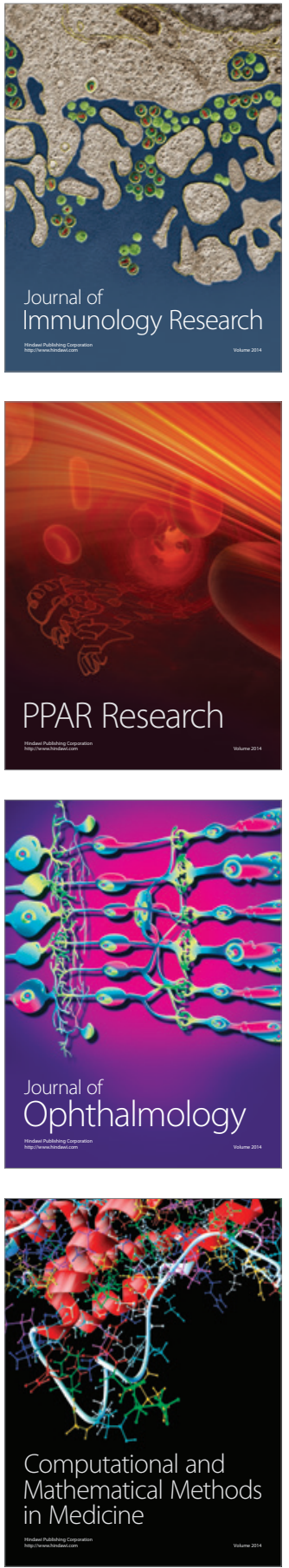

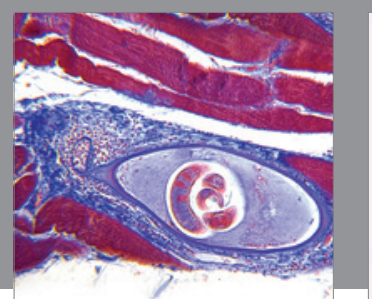

Gastroenterology Research and Practice

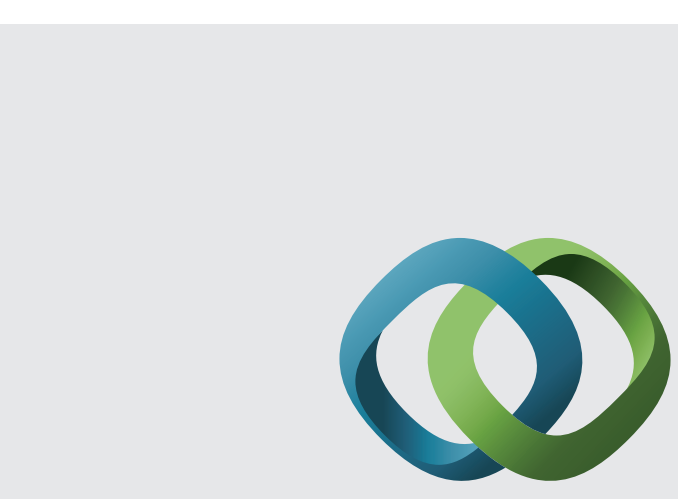

\section{Hindawi}

Submit your manuscripts at

http://www.hindawi.com
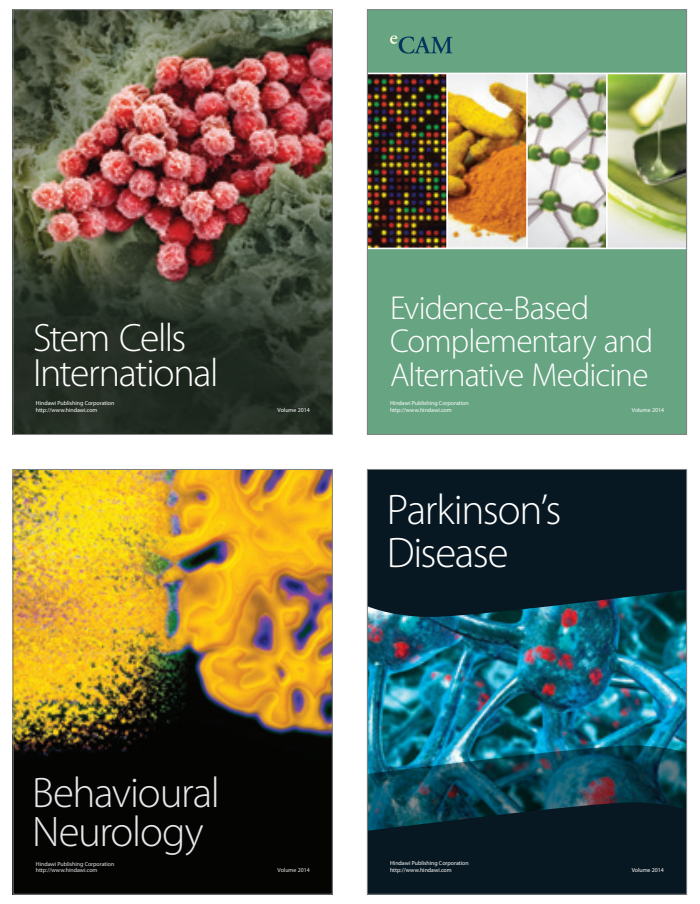
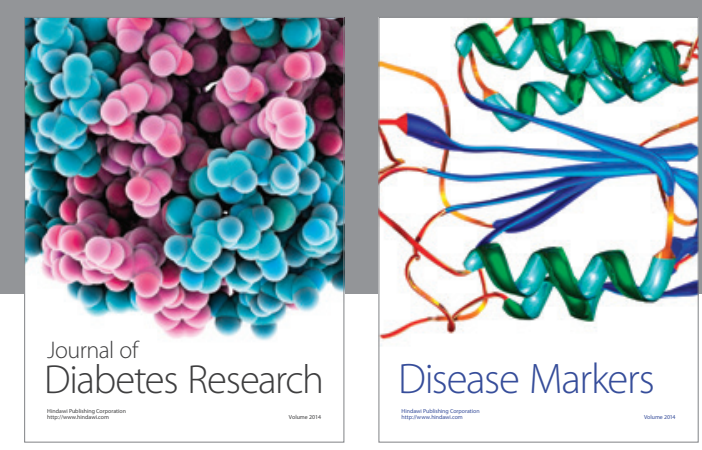

Disease Markers
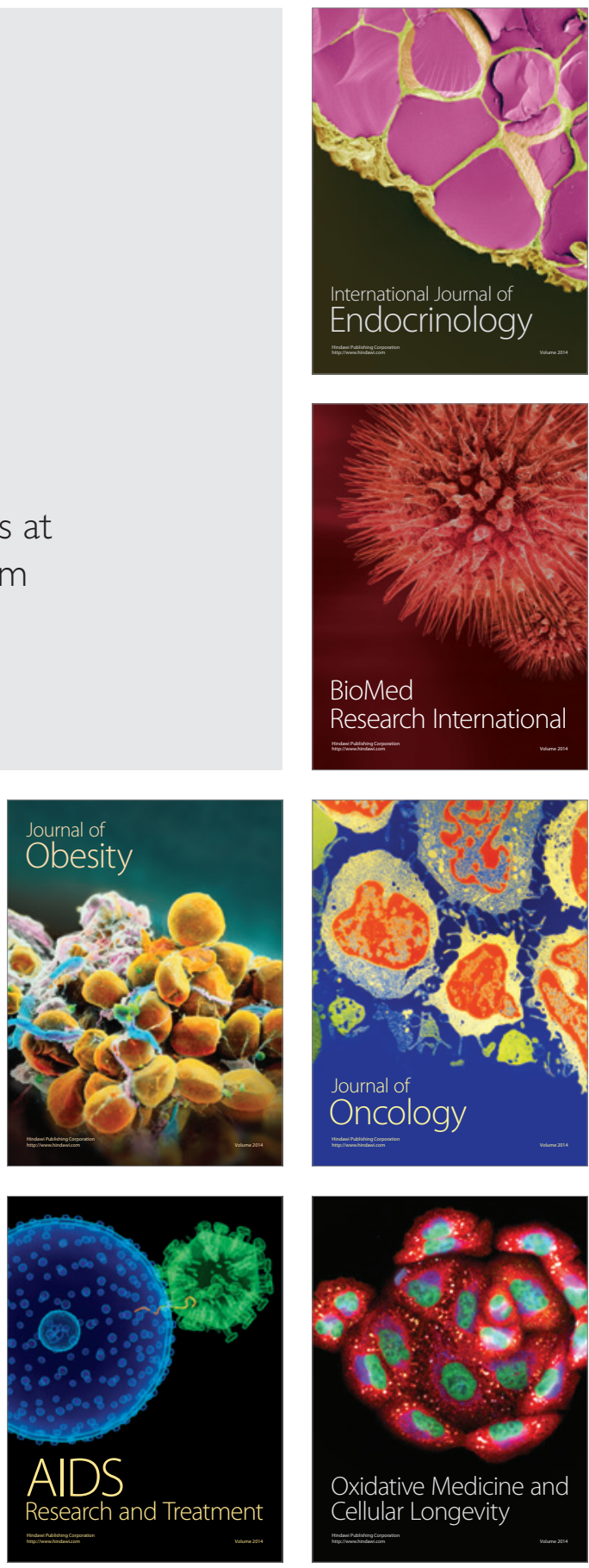